\title{
Reference:
}

The final publication is available at Springer via doi:10.1007/s11205-016-1526-8.

Subramaniam, Thirunaukarasu, Loganathan, Nanthakumar, Yerushalmi, Erez, Devadason, Evelyn Shyamala and Majid, Mazlan. (2016) Determinants of infant mortality in older ASEAN economies. Social Indicators Research (In Press).

\section{Determinants of Infant Mortality in Older ASEAN Economies}

\author{
Thirunaukarasu Subramaniam \\ Department of Southeast Asian Studies \\ Faculty of Arts and Social Sciences, University of Malaya \\ 50603 Kuala Lumpur, Malaysia \\ Email: stkarasu@um.edu.my \\ Nanthakumar Loganathan \\ Faculty of Management, Universiti Teknologi Malaysia \\ 81310 Johor Bahru, Johor, Malaysia \\ Email: n4nantha@yahoo.com
}

\section{Erez Yerushalmi}

Warwick Institute for Employment Research, University of Warwick

Coventry, United Kingdom

Email: E.Yerushalmi@warwick.ac.uk

\section{Evelyn Syamala Devadason}

Faculty of Economics and Administration, University of Malaya

50603 Kuala Lumpur, Malaysia

Email: evelyns@um.edu.my

\section{Mazlan Majid}

Faculty of Arts and Social Sciences, University of Malaya

50603 Kuala Lumpur, Malaysia

mazlanmajid@um.edu.my 


\begin{abstract}
Infant mortality in the Association of Southeast Asian Nations (ASEAN) has been declining, yet disparities remain between the nations. This paper therefore explores the determinants of infant mortality in the older ASEAN economies, Malaysia, Thailand, Indonesia and the Philippines. The key findings of the study are: First, there is evidence of long-run relationships among infant mortality, education, female fertility, income and access to healthcare. Second, the determinants of infant mortality vary between countries. Female fertility emerged as the main determinant of infant mortality in Malaysia, while access to healthcare matter for infant mortality in Indonesia and somewhat in the Philippines. The income effect is significant for reducing infant mortality in Malaysia, while female education level is important for Indonesia and Thailand. Third, the speed of adjustment of infant mortality rate is comparatively low in ASEAN-4.
\end{abstract}

Keywords: ASEAN; Infant mortality; Female fertility; Female education; Income; Healthcare

\title{
1. Introduction
}

Countries with high per capita income generally have low infant mortality rates (Tresserras et al., 1992; WHO, 2012), due to better access to healthcare facilities. The infant mortality rate is one of the most important indicators to measure the health of a population. It is defined as the number of children who die before reaching their first birthday in a given year, expressed per 1,000 live births (WHO, 2012). Higher per capita income countries provide better access 
to education and health which results in higher health literacy rates. This is further translated into better healthcare settings. Following which, there will be improvement in the population's health outcomes, such as reductions in infant and child mortality and increases in life expectancy. This phenomenon can be observed in the most advanced economy of Southeast Asia, Singapore, which has a relatively high per capita income and low rate of infant mortality. Singapore's infant mortality, for example, had declined from 12.0 (1980) to 2.2 (2012). Singapore is excluded from the analysis as higher income and education causes further progress in these variables to be less important in a reduction in infant mortality (see for example Schell et al, 2007).

In contrast, Indonesia has displayed much higher infant mortality rates than Singapore. Figure 1 shows that in Indonesia, it declined from 85.4 to 27.4. Clearly, Indonesia and the Philippines have the highest infant mortality among the four Association of Southeast Asian Nation (ASEAN) countries, due to its population size. While infant mortality has fallen in ASEAN-4 suggesting that it is moving on the right track, disparities remain between nations. The leading causes of child death in ASEAN are due to preventable afflictions, such as diarrhea, followed by pneumonia. Further, child deaths that occur in the neo-natal (first month of life) has been increasing relative to child deaths in the older stages of infancy (World Bank, 2014).

\section{(INSERT FIGURE 1 HERE)}

It is therefore worth examining the key determinants of infant mortality in ASEAN, which could provide a starting point for policy recommendations. While previous work seems to cite the disparities in infant mortality between older and newer ASEAN members, the disparities in infant mortality between the older members are often downplayed. This 
paper, thus, takes on the issue of infant mortality in the older ASEAN members. The paper is organized as follows. The next section reviews the literature on infant mortality to identify its core determinants. Following which, the data and model specification are elaborated in the third section. The fourth section details the empirical strategy adopted for this study. The fifth section reports the results and the final section concludes.

\section{Literature Review}

The theory of Demographic Transition proposes three stages of transition. The first stage is represented by high birth rates and death rates, the second stage by falling death rates and high birth rates, while the third stage is represented by falling birth rates and lower death rates (see Todaro \& Smith, 2003; National Academy of Sciences, 1963). This theory does not accurately describe the position of individual countries, even ASEAN, as many countries have passed through the stages very quickly due to faster economic and social change. It is therefore important to move beyond examining infant mortality solely based on stages of economic development, by considering potential factors that contribute to child deaths. The following details the core determinants derived from the literature.

Gbesemete and Jonsson (1993) found that infant mortality has an inverse relationship with the level of income. Following which, some studies have examined infant mortality during episodes of economic downturn. For example, Cruces et al. (2012) proved that infant mortality increased during the 2001-2002 economic crisis in Argentina. Likewise, Paxson and Schady (2005) confirmed similar findings in Peru during the 1988-1992 macroeconomic crises. Recent studies that allude to per capita income as an important determining factor for reducing infant mortality include Alvez and Belluzzo (2004), Hakobyan et al. (2006) and Renton et al. (2012). Other studies have qualified the inverse relationship between income per capita and infant mortality. For example, Kunitz et al. (1987) found that the economic 
crisis, which began in 1979 in Yugoslavia, did not have a severe impact on infant mortality among the poorer population compared to the more favored populations. Haines (2011) noted that the father's educational status is important for understanding infant mortality in households in the United States (US); households with heads engaged in professional and managerial work experienced lower infant mortality compared to that of non-farm laborers. Ko et al. (2014) also agreed that low parental employment status is associated with infant mortality in preterm infants but not in full-term infants.

Apart from income, Gbesemete and Jonsson (1993) highlighted the inverse relationship between infant mortality with access to healthcare. As access to healthcare improves, through supply-side health care reforms, infant mortality among the poor reduces (see also Gruber et al., 2014). Hakobyan et al. (2006) and Seid (2012) found an inverse relationship between infant mortality and healthcare infrastructure for Armenia and Ethiopia, respectively. Furthermore, Frankenburg (1995) has argued that, the access to maternity clinics and doctors reduces the risk of infant mortality in the case of Indonesia. Zakir and Wunnava (1999) also cited that the broader the access to healthcare, the lower will be the infant mortality in a cross-sectional analysis of 117 countries. Notwithstanding the general consensus on the negative relationship between access to healthcare and infant mortality, a rather unusual result or paradox was cited by Matsaganis (1992). The author found that Athens and Salonica (modern, prosperous cities with high standards of education and better access to medical care) actually experienced very high levels of infant mortality.

Infant mortality is also linked to educational levels. Most of the studies done worldwide found that infant mortality is inversely related with maternal education or female education. These include studies done by Gbesemete and Jonsson (1993), Matsaganis (1992), Defo (1996) and Mondal et al. (2009). In the case of Bangladesh, Mondal et al. (2009) pointed out that the risks of neonatal and child mortality are 31.4 per cent and 24.1 per cent 
lower among women having secondary and higher education, respectively, than those having no education. Similarly, Alvez and Belluzzo (2004) stated that education is by far the most important factor for reducing infant mortality, as one additional year of schooling leads to a decline of more than 7 per cent in average infant mortality rates. Studies by Hakobyan et al. (2006) and Renton et al. (2012) supported the results obtained by Alvez and Belluzzo (2004). Ko et al. (2014) further agreed that paternal and maternal education levels were inversely related to infant mortality in preterm and full-term infants, based on multivariate adjusted logistic models.

Another important indicator of infant mortality is female fertility. Most of the researchers found a positive relationship between infant mortality and female fertility (see for example Kalipeni, 1993; Knodel, 1968; Bailey, 1989; Gbesemete and Jonsson, 1993; Gani, 1999; Blau, 1986; Schultz, 1993; Narayan \& Peng, 2006 and Handa, 2000). In short, when infant mortality increases, female fertility also tends to increase. However, there are also some contradictory findings, namely studies done by Hondroyiannis and Papapetrou (2002) for Finland and Narayan and Peng (2007) for Japan.

From the review of the literature, several important indicators of infant mortality are identified. The indicators are income, access to healthcare, female education and female fertility.

\section{Data Source and Empirical Strategy}

In this paper, time data series for the period 1980-2012 was compiled in four ASEAN countries, namely Malaysia, Thailand, Indonesia and the Philippines. The data used in this study, which mainly focuses on infant mortality rate $(I M R)$, female fertility rate $(F R)$, access 
to health $(P H Y)$, income $(G N I)$ and female education $(E D U C)$, were extracted from the World Development Indicators (CD-ROM, 2014).

The model specification, expressed in logarithmic form, is based on Cumper (1984) and Gbesemete and Jonsson (1993) as follows:

$\operatorname{lnIMR}_{t}=\beta_{0}+\beta_{1} \operatorname{lnFR} R_{t}+\beta_{2} \ln P H Y_{t}+\beta_{3} \ln G N I_{t}+\beta_{4} \ln E D U C_{i t}+\mu_{t}$

where $\mu$ is the stochastic error term and $\beta_{0}$ is the intercept term. All variables are as previously defined.

The study follows a sequential process in terms of the empirical strategy to estimate the equation (1). This includes the test for unit root, followed by the cointegration analysis and finally the short- and long-run impacts of the determinants of infant mortality. The following details the strategies adopted. First, unit root tests are performed for all variables to identify if the variables are integrated in the following order : $I(0)$ or $I(1)$ or a mixture of both, avoiding the $I(2)$ indication (Ohlan, 2015). The Augmented Dickey-Fuller (ADF) (Dickey \& Fuller, 1979) test is employed for this purpose. To strengthen the unit root findings, we also emphasize the Zivot and Andrew (1992) unit root test which able to capture break point for each series used in this study. Basically, ZA unit root test is able to capture the unknown single break in the deterministic trend of the series.

Second, given that the time-series data was found to have different orders of integration, namely $I(0) / I(1)$, Pesaran et al. (2001) proposed using an autoregressive distributed lag approach (ARDL) to test for cointegration. This method is much more robust than the Engle- 
Granger cointegration approach (Engle et al., 1989) to investigate the existence of long-run relationships amongst the variables. The ARDL bounds testing model is written as follows:

$$
\begin{aligned}
\Delta I M R_{t} & =\beta_{0}+\sum_{i=1}^{n} \alpha_{1} \Delta I M R_{t-i}+\sum_{i=0}^{n} \alpha_{2} \Delta F R_{t-i}+\sum_{i=0}^{n} \alpha_{3} \Delta P H Y_{t-i}+\sum_{i=0}^{n} \alpha_{4} \Delta G N I_{t-i}+ \\
& \sum_{i=0}^{n} \alpha_{5} \Delta E D U C_{t-i}+\delta_{1} I M R_{t-i}+\delta_{2} F R_{t-i}+\delta_{3} P H Y_{t-i}+\delta_{4} G N I_{t-i}+\delta_{5} E D U C_{t-i}+\varepsilon_{1 t}
\end{aligned}
$$

$$
\begin{aligned}
\Delta F R_{t}= & \beta_{0}+\sum_{i=1}^{n} \alpha_{1} \Delta F R_{t-i}+\sum_{i=0}^{n} \alpha_{2} \Delta I M R_{t-i}+\sum_{i=0}^{n} \alpha_{3} \Delta P H Y_{t-i}+\sum_{i=0}^{n} \alpha_{4} \Delta G N I_{t-i}+ \\
& \sum_{i=0}^{n} \alpha_{5} \Delta E D U C_{t-i}+\delta_{1} F R_{t-i}+\delta_{2} I M R_{t-i}+\delta_{3} P H Y_{t-i}+\delta_{4} G N I_{t-i}+\delta_{5} E D U C_{t-i}+\varepsilon_{2 t}
\end{aligned}
$$

$$
\begin{aligned}
\Delta P H Y_{t} & =\beta_{0}+\sum_{i=1}^{n} \alpha_{1} \Delta P H Y_{t-i}+\sum_{i=0}^{n} \alpha_{2} \Delta I M R_{t-i}+\sum_{i=0}^{n} \alpha_{3} \Delta F R_{t-i}+\sum_{i=0}^{n} \alpha_{4} \Delta G N I_{t-i}+ \\
& \sum_{i=0}^{n} \alpha_{5} \Delta E D U C_{t-i}+\delta_{1} P H Y_{t-i}+\delta_{2} I M R_{t-i}+\delta_{3} F R_{t-i}+\delta_{4} G N I_{t-i}+\delta_{5} E D U C_{t-i}+\varepsilon_{3 t}
\end{aligned}
$$

$$
\begin{aligned}
\Delta G N I_{t} & =\beta_{0}+\sum_{i=1}^{n} \alpha_{1} \Delta G N I_{t-i}+\sum_{i=0}^{n} \alpha_{2} \Delta I M R_{t-i}+\sum_{i=0}^{n} \alpha_{3} \Delta F R_{t-i}+\sum_{i=0}^{n} \alpha_{4} \Delta P H Y_{t-i}+ \\
& \sum_{i=0}^{n} \alpha_{5} \Delta E D U C_{t-i}+\delta_{1} G N I_{t-i}+\delta_{2} I M R_{t-i}+\delta_{3} F R_{t-i}+\delta_{4} P H Y_{t-i}+\delta_{5} E D U C_{t-i}+\varepsilon_{4 t}
\end{aligned}
$$

$$
\Delta E D U C_{t}=\beta_{0}+\sum_{i=1}^{n} \alpha_{1} \Delta E D U C_{t-i}+\sum_{i=0}^{n} \alpha_{2} \Delta I M R_{t-i}+\sum_{i=0}^{n} \alpha_{3} \Delta F R_{t-i}+\sum_{i=0}^{n} \alpha_{4} \Delta P H Y_{t-i}+
$$




$$
\sum_{i=0}^{n} \alpha_{5} \Delta G N I_{t-i}+\delta_{1} E D U C_{t-i}+\delta_{2} I M R_{t-i}+\delta_{3} F R_{t-i}+\delta_{4} P H Y_{t-i}+\delta_{5} G N I_{t-i}+\varepsilon_{5 t}
$$

In equations (2a) - (2e), $\Delta$ is the first difference operator. The null hypothesis of no cointegration among the variables is tested. This is done by conducting a joint-significance test of the lagged levels of the variables. As such, the null hypothesis states that all the coefficients of the lagged level variables are equal to zero. The null and the alternative hypothesis are thus formulated as follows:

$$
\begin{aligned}
& H_{0}: \alpha_{1}=\alpha_{2}=\alpha_{3}=\alpha_{4}=\alpha_{5}=0 \\
& H_{0}: \alpha_{1} \neq \alpha_{2} \neq \alpha_{3} \neq \alpha_{4} \neq \alpha_{5} \neq 0
\end{aligned}
$$

We used the $F$ test to determine whether a long-run relationship exists between the variables. When a long-run relationship exists among the variables, the $F$ test results will show which variable should be normalized. A long-run relationship exists among the variables if the calculated $F$-statistics is found to be greater than the upper critical bound (UCB), and if the calculated $F$-statistics is below the lower critical bound (LCB), a long-run relationship does not exist. Finally, if the calculated $F$-statistics are found to fall between the $\mathrm{LCB}$ and the $\mathrm{UCB}$, we then conclude that the test for the existence of a long-run relationship is inconclusive. As mixed lag condition emerged in recent studies when the Akaike Information Criterion (AIC), Schwarz Information Criterion (SBC) and Hannan-Quinn Information Criterion (HQC) are used, we therefore decided to employ Hatemi-J Criterion (HJC) (2003) as lag selection criteria in this study. According to Hatemi-J (2003), this criterion is based on the fundamental lag selection condition from the SBC introduced by 
Schwarz (1978) and the HQC formulated by Hannan and Quinn (1979). Generally, this HJC approach is suitable for non-stationary series and the basis for this criterion is as follows:

$\mathrm{HJC}=\ln (\operatorname{det} \widehat{\Omega})+j\left(\frac{n^{2} \ln T+2 n^{2} \ln (\ln T)}{2 T}\right)$

Where, $\Omega$ represent the maximum likelihood estimate of the variance and covariance matrix and $\mathrm{T}$ is the total sample size. This HJC will perform well in selecting the optimal lag of the VAR estimation because it's combining both SBC and HQC in a single equation as indicated in equation (4). The minimum value of the HJC will represent the optimal lag order for the VAR estimates used in this study to capture the lag order.

Next, we carried out the ARDL- Error Correction Model (ECM) framework to identify the long and short-run cointegrations. The error correction term (ECT) will represent the long-run causality effect, when the t-ratio is statistically significant. The ARDL-ECM models based on long- and short-run relationships are expressed as follows:

$$
\begin{aligned}
{\left[\begin{array}{c}
\Delta I M R_{t} \\
\Delta F R_{t} \\
\Delta P H Y_{t} \\
\Delta G N I_{t} \\
\Delta E D U C_{t}
\end{array}\right]=} & {\left[\begin{array}{l}
\beta_{1} \\
\beta_{2} \\
\beta_{3} \\
\beta_{4} \\
\beta_{5}
\end{array}\right]+\left[\begin{array}{lllll}
\beta_{11,1} & \beta_{12,1} & \beta_{13,1} & \beta_{14,1} & \beta_{15,1} \\
\beta_{21,1} & \beta_{22,1} & \beta_{23,1} & \beta_{24,1} & \beta_{25,1} \\
\beta_{31,1} & \beta_{32,1} & \beta_{33,1} & \beta_{34,1} & \beta_{35,1} \\
\beta_{41,1} & \beta_{42,1} & \beta_{43,1} & \beta_{44,1} & \beta_{45,1} \\
\beta_{51,1} & \beta_{52,1} & \beta_{53,1} & \beta_{54,1} & \beta_{55,1}
\end{array}\right]\left[\begin{array}{c}
\Delta I M R_{t-1} \\
\Delta F R_{t-1} \\
\Delta P H Y_{t-1} \\
\Delta G N I_{t-1} \\
\Delta E D U C_{t-1}
\end{array}\right]+\cdots \cdots+} \\
& {\left[\begin{array}{llllll}
\beta_{11, i} & \beta_{12, i} & \beta_{13, i} & \beta_{14, i} & \beta_{15, i} \\
\beta_{21, i} & \beta_{22, i} & \beta_{23, i} & \beta_{24, i} & \beta_{25, i} \\
\beta_{31, i} & \beta_{32, i} & \beta_{33, i} & \beta_{34, i} & \beta_{35, i} \\
\beta_{41, i} & \beta_{42, i} & \beta_{43, i} & \beta_{44, i} & \beta_{45, i} \\
\beta_{51, i} & \beta_{52, i} & \beta_{53, i} & \beta_{54, i} & \beta_{55, i}
\end{array}\right]\left[\begin{array}{c}
\Delta I M R_{t-i} \\
\Delta F R_{t-i} \\
\Delta P H Y_{t-i} \\
\Delta G N I_{t-i} \\
\Delta E D U C_{t-i}
\end{array}\right]+\left[\begin{array}{l}
\mu_{1, t} \\
\gamma_{2} \\
\gamma_{3} \\
\gamma_{4} \\
\gamma_{5}
\end{array}\right] \times E C T_{t-1}+\left[\begin{array}{l}
\mu_{2, t} \\
\mu_{3, t} \\
\mu_{5, t}
\end{array}\right] }
\end{aligned}
$$


In equation (4), $\Delta$ denotes the difference operator; $E C T_{t-1}$ is the lagged error correction terms $\mu_{1, t}, \mu_{2, t}, \mu_{3, t}, \mu_{4, t}$ and $\mu_{5, t}$ are serial independent random errors.

\section{Results and Discussion}

The different data characteristics provided by the descriptive statistics in Table 1 lead us to the question whether the correlations among the variables are due to the empirical model estimations. The results of Jarque-Bera (JB) test reveal that the dataset for all countries being investigated are normally distributed, except for $F R$ in Indonesia and Philippines; and EDUC for Malaysia, whereby the presence of non-normal distribution is identified.

\section{(INSERT TABLE 1 HERE)}

The augmented Dickey-Fuller (ADF) unit root test results are reported in Table 2. The results reveal that the variables of mixed order of integration, with $I(0)$ and $I(1)$ for Indonesia $(F R)$ and Malaysia $(E D U C)$, while the variables for the Philippines and Thailand follow the I(1) stationary process. While, the ZA results show that, all series has rejected the null hypothesis at $I(1)$, except the $F R$ series for Indonesia and Malaysia. This condition is in line with the ADF test results and this indicate a mixed stationary condition for both countries. Interestingly, we found break date with almost similar periods for most of the older ASEAN countries. For example, the GNI series break date is captured during the period of 1997-1998 for all countries. While, other series break dates are not matching to each other. As we have a mixed order of integration among the series, we proceeded with the ARDL cointegration estimation method as suggested by Pesaran et al. (2001) and Narayan (2005). 
(INSERT TABLE 2 HERE)

Before estimating the ARDL model, we determined the optimal lag using the Vector Autoregressive (VAR) framework. Table 3 shows the optimal lag selection for all four countries. The values in the brackets indicate the optimal lag selected for each country. Since the mixed lag condition issue arises in our study, we have decided to use the HJC and the optimal lag condition using $\mathrm{HJC}$ is equal to 4. Therefore, throughout the ARDL model estimation, we emphasis the optimal lag as 4 to determine the cointegration in the short and long-run condition.

(INSERT TABLE 3 HERE)

After determining the optimal lags for each country, we then estimated the ARDL bounds testing. We singled out the ARDL models for each country based on the maximum lags equal to 4 . The estimated results of the $F$-bounds are provided in Table 4 . The results indicate that long-run relationships existed among the variables being studied at the 1 per cent level of significance, as the calculated $F$-statistics falls above the 1 per cent UCB of 4.370 . In short, long run relationships exist between infant mortality with female education attainment, income, female fertility and access to healthcare.

(INSERT TABLE 4 HERE)

After establishing the existence of the cointegration relationship among the variables, we further proceeded with the long- and short-run impacts of these independent variables 
with infant mortality rate. Table 5 reports the results, which could be interpreted as the elasticity between the independent variables with infant mortality rates. For example, a $1 \%$ rise in the access to healthcare lowers the infant mortality rate by $0.23 \%$ in Indonesia and $0.02 \%$ in the Philippines.

\section{(INSERT TABLE 5 HERE)}

Overall, our main conclusion is that the main drivers affecting infant mortality rates are different among the various countries. For example, in Indonesia, access to healthcare (PHY) and female education (EDUC) are found to be significant for reducing infant mortality at the $5 \%$ and $10 \%$ respectively, confirming findings from previous studies. In other words, raising access to healthcare and female education by $1 \%$ would lower infant mortality rate by $0.23 \%$ and $0.24 \%$, respectively. Specifically, Frankenburg's (1995) study for Indonesia revealed that health services do significantly alter infant mortality risks; adding maternity clinics and doctors to villages reduce the risks of infant mortality. Bourne and Walker (1991); and Bhīma and Stratified (1991) for example, found a positive effect of education on the survival of a child. Satyr (1997) also found that the risk of death is negatively associated with mother's education.

For Malaysia, the main determinant of infant mortality is income. Income (GNI) had the expected negative sign and is found to be highly significant at the $1 \%$ level, which concurs with studies done by Erdogan et al. (2013). Thus, a 1\% increase in income lowers the infant mortality rate by $0.7 \%$ as access to health improves when income rises, thus reducing infant mortality. Fertility (FR), however, is negatively associated with infant mortality. However, this is not surprising as Hondroyiannis and Papapetrou (2002) also found a negative association between female fertility and infant mortality in Finland.

In the case of the Philippines, access to healthcare is found to be significant at the 5 percent level. It had the expected negative sign as per the theory, though its effect of reducing 
infant mortality is rather low - only $0.022 \%$. This finding is supported by Hanmer et al. (2003) who had concluded that a greater number of doctors per people reduce infant mortality. Likewise, female fertility rate had the expected positive relationship with infant mortality. Income, however, displayed a positive effect on infant mortality, which contradicts earlier findings by Zakir and Wunnava (1999), i.e., one naturally expects a negative relationship between income and mortality.

Lastly, for Thailand, female education is found to be inversely related; a dominant driver that affects infant mortality. This suggests that higher the education level, the better the knowledge that women have regarding healthcare, which would lower infant mortality. Conversely, and as expected, fertility rate had a positive and a dominant relationship with infant mortality, at the $1 \%$ confidence level. Access to healthcare is also found to be positively related with infant mortality, contradicting the results of Gruber et al. (2014). A plausible explanation for this is provided by Kaplan et al. (2015), as they found that in remote areas with minimal access to medical services, a short interval between births increases the mortality risk to the subsequent infant by fourfold.

Finally, the short-run relationships between the variables, based on the ARDL-ECM approach, are reported in Table 6. We find that the estimated lagged error correction term $\left(E C T_{t-1}\right)$ fulfills the negative sign and is found to be significant in all four countries. The speed of adjustment for all countries is considered to be unbalanced and low. The results suggested that for the Philippines, the adjustment to equilibrium following a shock is approximately $10 \%$, while for the other remaining countries; adjustment to equilibrium following a shock is lower, the lowest being in Indonesia at below 5\%.

(INSERT TABLE 6 HERE) 
We also evaluated the regression coefficients for structural stability by using two measures, namely the cumulative sum (CUSUM) and the cumulative sum of squares (CUSUMSQ) of the recursive residual test (Figure 2). We found that both the CUSUM and CUSUMSQ test statistics did not exceed the 5\% level of significance bounds. This indicates that the regression equations are rather stable.

(INSERT FIGURE 2 HERE)

\section{Concluding Remarks}

This paper investigates the main drivers behind infant mortality in Indonesia, Malaysia, Philippines and Thailand. To do this, we used an autoregressive distributed lag (ARDL) Error Correction Model (ECM) framework to test for cointegration and identify the long and shortrun cointegrations of female fertility rates, access to healthcare, income, and female education levels. We find that the main drivers behind infant mortality are differences among the various countries. Policy makers should therefore develop appropriate policies to address this. For example, improving access to healthcare in Indonesia and the Philippines (the two lower middle income countries) lowers infant mortality, and should therefore be a top priority. Female education is an important driver in Indonesia and Thailand for lowering infant mortality rates, while income is an important factor in Malaysia. The preventable infant deaths caused by diarrhea and pneumonia, cited in ASEAN, further underscore the importance of access to healthcare. Future studies should focus on the importance of access to healthcare for neo-natal mortality in the lower income countries of ASEAN.

\section{References}


Bailey, M. (1989). Determinants of fertility in a rural society: some evidence from Sierra Leone. Social Science \& Medicine, 28(3), 285-292.

Bourne, K. L., \& Walker, G. M. (1991), The Differential Effect of Mother's Education on Mortality of Boys and Girls in India. Population Studies, 45, 203-219.

Cruces, G., Glzmann, P., \& Calva, L. F. L (2012). Economic crises, maternal and infant mortality, low birth weight and enrollment rates: evidence from Argentina's downturns. World Development, 40(2), 303-314.

Cumper, G. E. (1984). Determinants of Health Levels in Developing Countries. Letchwood, UK, Research Studies Press Ltd.

Defo, B. K. (1996). Areal and socioeconomic differentials in infant and child mortality in Cameroon. Social Science \& Medicine, 42(3), 399-420.

Erdogan, E., Ener, M., \& Arica, F. (2013). The strategic role of infant mortality in the process of economic growth: an application for high income OECD countries. Procedia Social and Behavioral Sciences, 99, 19-25.

Frankenburg, E. (1995). The effects of access to health care on infant mortality in Indonesia. Health Transit Review, 5(2), 143-163.

Gbesemete, K.P., \& Jonsson, D. (1993). A comparison of empirical models on determinants of infant mortality: a cross-national study on Africa. Health Policy, 24, 155-174.

Gruber, J., Hendren, N., \& Townsend, R. M. (2014). the great equalizer: health care access and infant mortality in Thailand. American Economic Journal Applied Economics, 6(1), 91-107.

Haines, M. R. (2011). Inequality and infant and childhood mortality in The United States in the twentieth century. Explorations in Economic History, 48, 418-428.

Hakobyan, M., Mkrtchyan, A., \& Yepiskoposyan, L. (2006). Infant mortality in Armenia, 1992-2003. Economics and Human Biology, 4, 351-358. 
Handa, S. (2000). The impact of education, income, and mortality on fertility in Jamaica. World Development, 28(1), 173-186.

Hanmer, L., Lensink, R., \& White, H. (2003). Infant and child mortality in developing countries: analysing the data for robust determinants. The Journal of Development Studies, 40(1), 101-118.

Hondroyiannis, G., \& Papapetrou, E. (2002). Demographic transition in Europe. Economics Bulletin, 10(3), 1-8.

Hatemi-J, A. (2003). A new method to choose the optimal lag order in stable and unstable VAR models. Applied Economics Letters, 10(3), 135-137.

Kalipeni, E. (1993). Determinants of infant mortality in Malawi: a spatial perspective. Social Science \& Medicine, 37(2), 183-198.

Kaplan, H. S., Hooper, P. L., Stieglitz, J., \& Gurven, M. (2015). The causal relationship between fertility and infant mortality: prospective analyses of a population in transition. In Population in the Human Sciences: Concepts, Models, Evidence. Kreager, P., Winney, B., Ulijaszek, S., \& Capelli, C. Eds., Oxford University Press, 361-376.

Ko, Y. J., Shin, S. H., Park, S. M., Kim, H. S., Lee, J. Y., Kim, K. H., \& Cho, B. (2014). Effects of employment and education on preterm and full-term infant mortality in Korea. Public Health, 128(3), 254-261.

Kunitz, S. J., Simic, S., \& Odoroff, C. L. (1987). Infant mortality and economic instability in Yugoslavia. Social Science \& Medicine, 21, 953-960.

Matsaganis, M. (1992). Maternal mobility and infant mortality in Greece: a regional analysis. Social Science \& Medicine, 34(3), 317-323.

Mondal, M. N. I., Hossain, M. K., \& Ali, M. K. (2009). Factors influencing infant and child mortality: a case study of Rajshahi District, Bangladesh. Journal of Human Ecology, 26(1), 31-39. 
Narayan, P. K., \& Peng, X. (2007). Japan's fertility transition: empirical evidence from the bounds testing approach to cointegration. Japan and the World Economy, 19, 263-278.

Narayan, P. K., \& Peng, X. (2006). An econometric analysis of the determinants of fertility for China, 1952-2000. Journal of Chinese Economic and Business Studies, 4(2), 165183.

Narayan, P. K. (2005). The saving and investment nexus for China: evidence from cointegration tests. Applied Economics, 37(17), 1979-1990.

Nasreen, S., Anwar, S., \& Ahmad, N. (2012). Health status, income inequality and institutions: evidence from Pakistan economy. Pakistan Journal of Life and Social Sciences, 10(2), 139-144

Ohlan, R. (2015). The impact of population density, energy consumption, economic growth and trade openness on $\mathrm{CO}_{2}$ emissions in India. Natural Hazards, 79, 1409-1428.

Paxson, C., \& Schady, N. (2005). Child health and economic crisis in Peru. World Bank Economic Review, 19(2), 203-223.

Pesaran, M. H., Shin, Y., \& Smith, R. J. (2001). Bounds testing approaches to the analysis of level relationships. Journal of Applied Econometrics, 16(3), 289-326.

Renton, A., Wall, M., \& Lintott, J. (2012). Economic growth and decline in mortality in developing countries: an analysis of the World Bank development datasets. Public Health, 126(7), 551-560.

Schell, C. O., Reilly, M., Rosling, H., Peterson, S., \& Ekstrom, A. M. (2007). Socioeconomic determinants of infant mortality: a worldwide study of 152 low-, middle-, and high-income countries. Scandinavian Journal of Public Health, 35, 288297. 
Seid, E. H. (2012), Macroeconomic Conditions and Infant Mortality in Ethiopia: A Survival Analysis. Master in Economic Development and Growth, School of Economics and Management, Lund University.

Tresserras, R., Canela, J., Alvarez, J., Sentis, J., \& Salleras, L. (1992), Infant mortality, per capita income and adult illiteracy: an ecological approach. American Journal of Public Health, 82, 435-438.

World Bank. (2014a). World Development Indicators, Washington DC.

World Bank (2014b). Bridging the Development Gap: ASEAN Equitable Development Monitor 2014, Washington DC.

World Health Organization. (2012). Health at a Glance: Asia/Pacific 2012. OECD Publishing.

Zakir, M., \& Wunnava P. V. (1999). Factors affecting infant mortality rates: evidence from cross-sectional data. Applied Economics Letters, 6, 271-273.

Zivot, E., \& Andrews, D. (1992). Further evidence of great crash, the oil price shock and unit root hypothesis. Journal of Business \&Economic Statistics, 10, 251-270. 


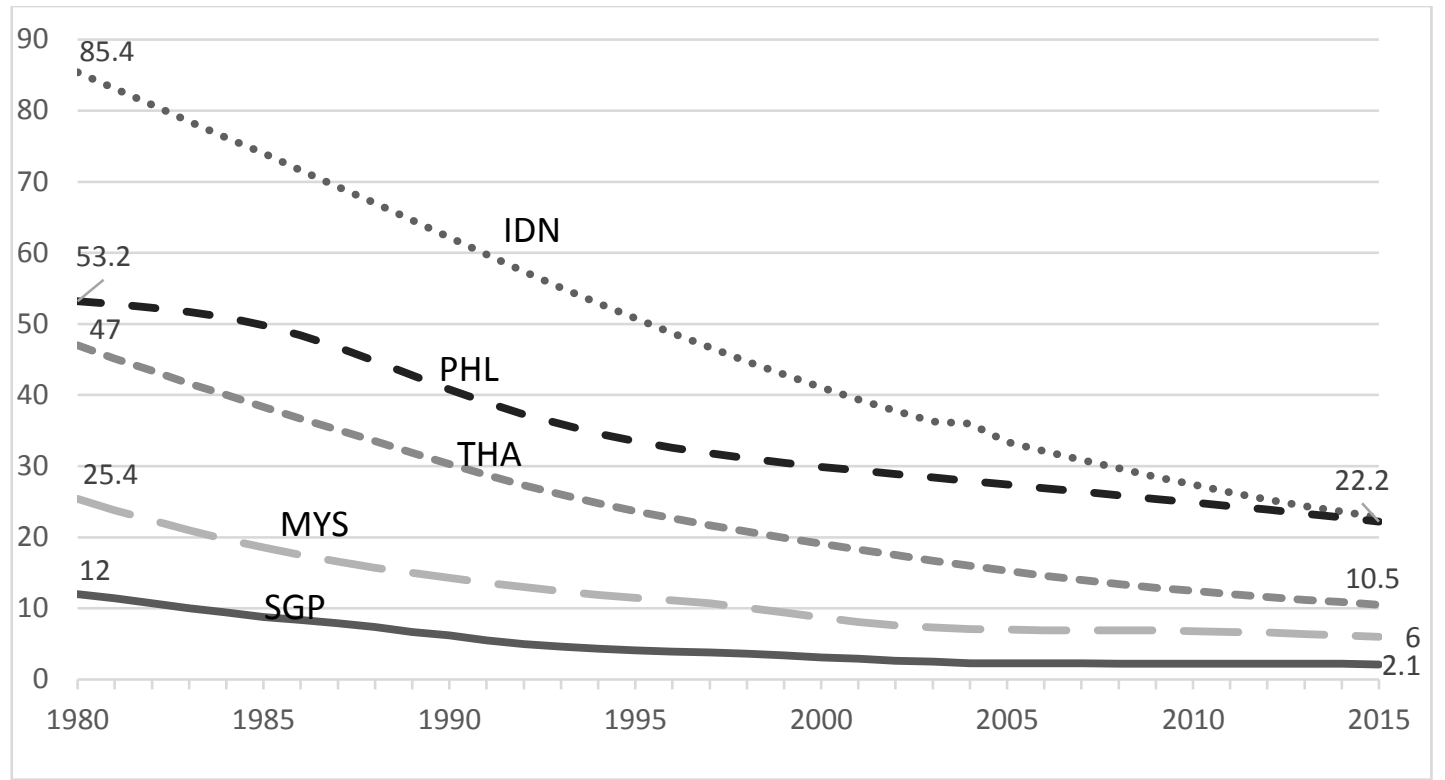

Note: SGP - Singapore; MYS - Malaysia; THA - Thailand; PHL - Philippines; IDN - Indonesia. Source: World Development Indicators (2016).

Fig 1 Infant mortality rate (per 1,000 live births) for selected ASEAN countries, 1980-2015 

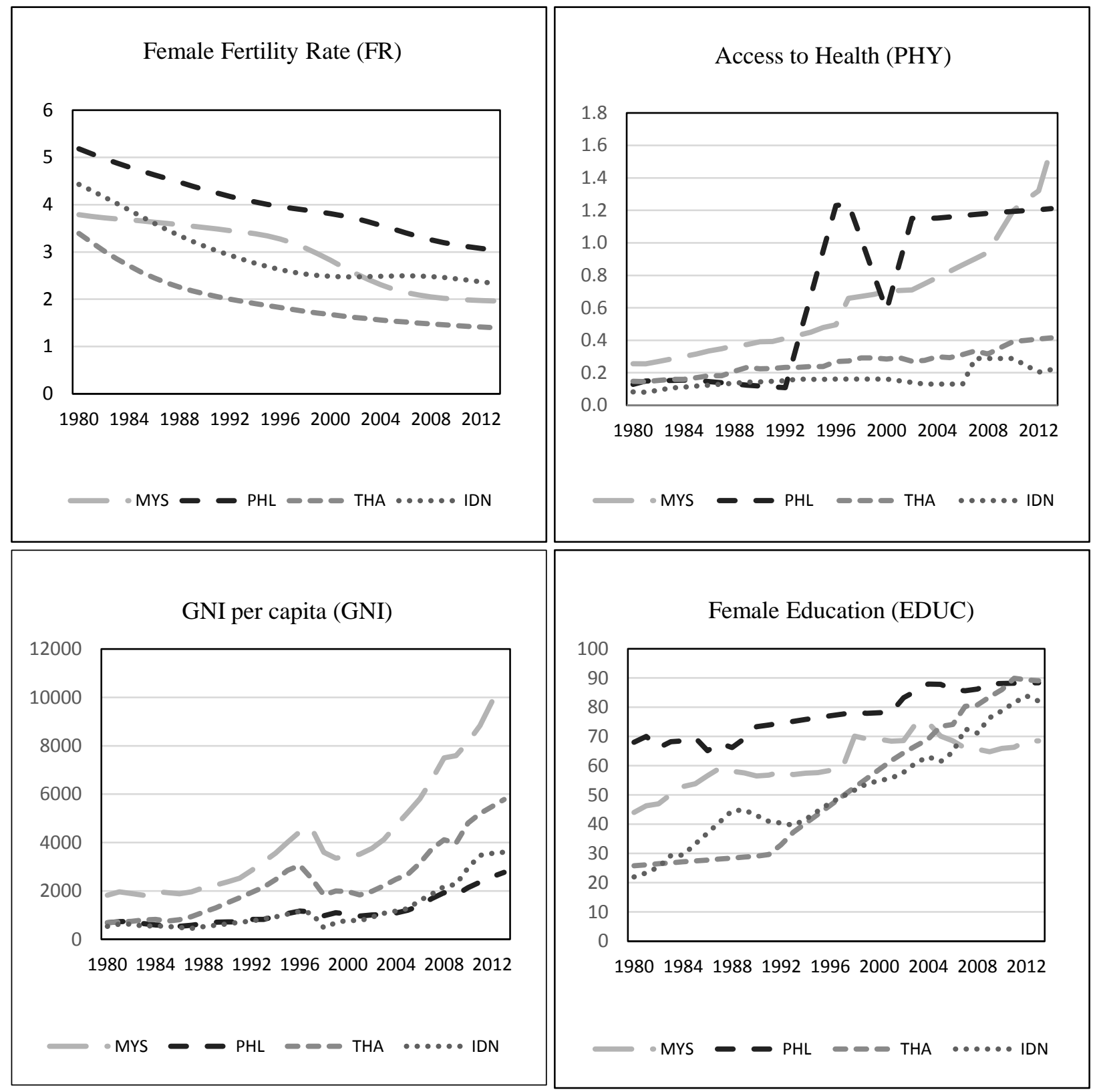

Notes: (1) MYS - Malaysia; THA - Thailand; PHL - Philippines; IDN - Indonesia. (2) Latest data available for $F R$ and GNI is 2014 and for $P H Y$ and EDUC is 2013.

Source: World Development Indicators (2016).

Fig 2 Key indicators for selected ASEAN countries, 1980-2013/14 


\section{Indonesia}
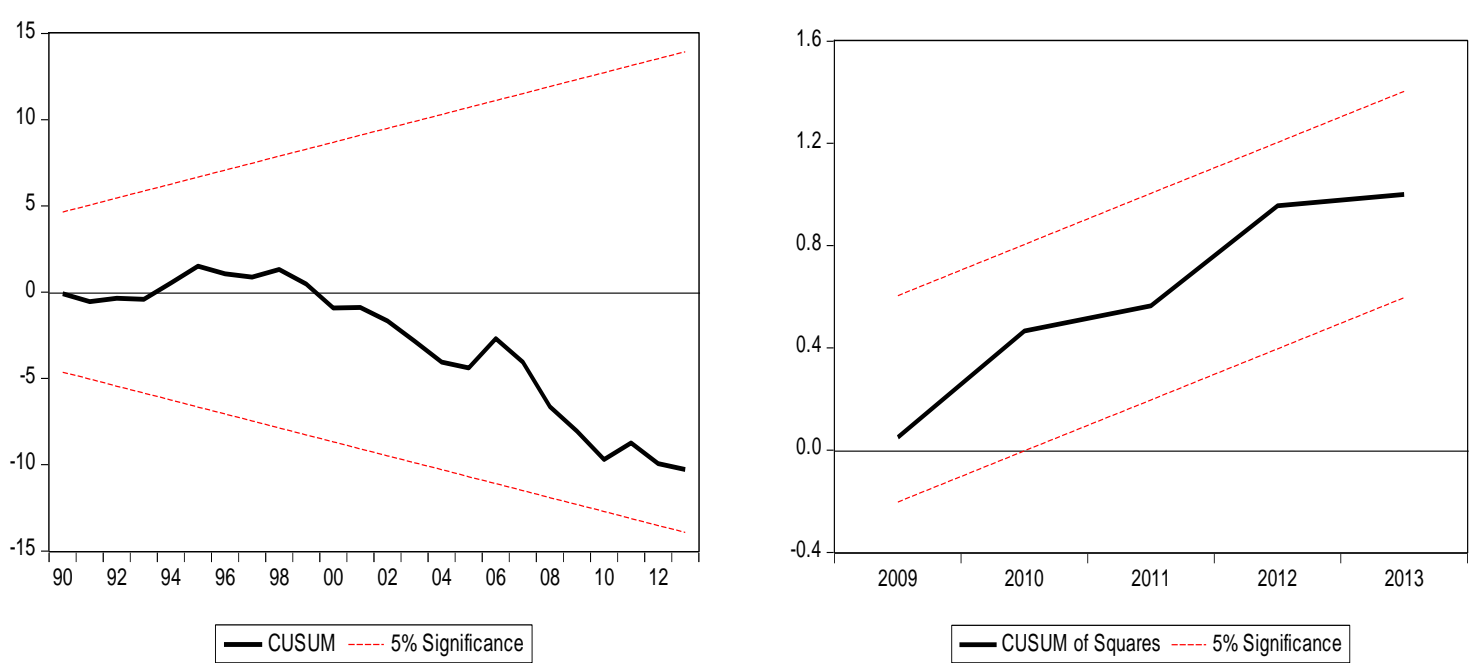

Malaysia
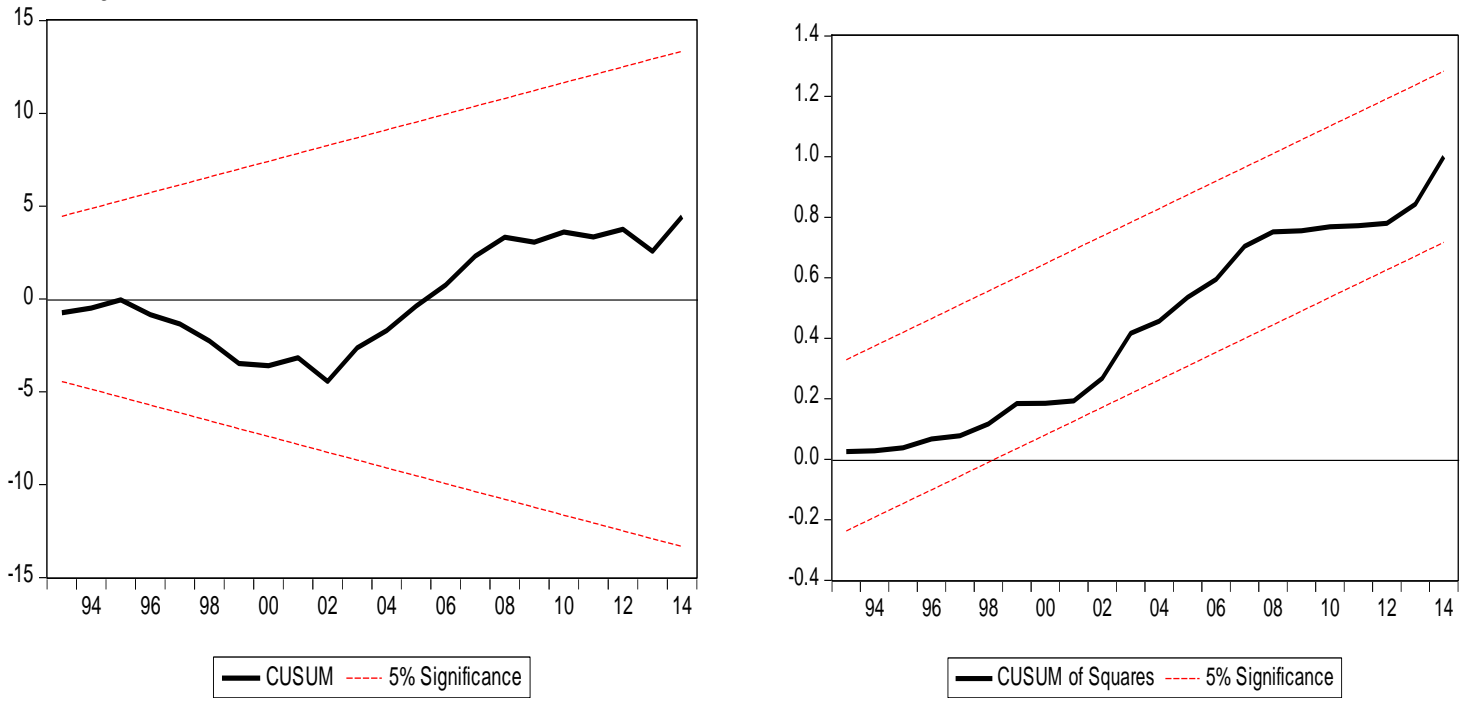


\section{Philippines}
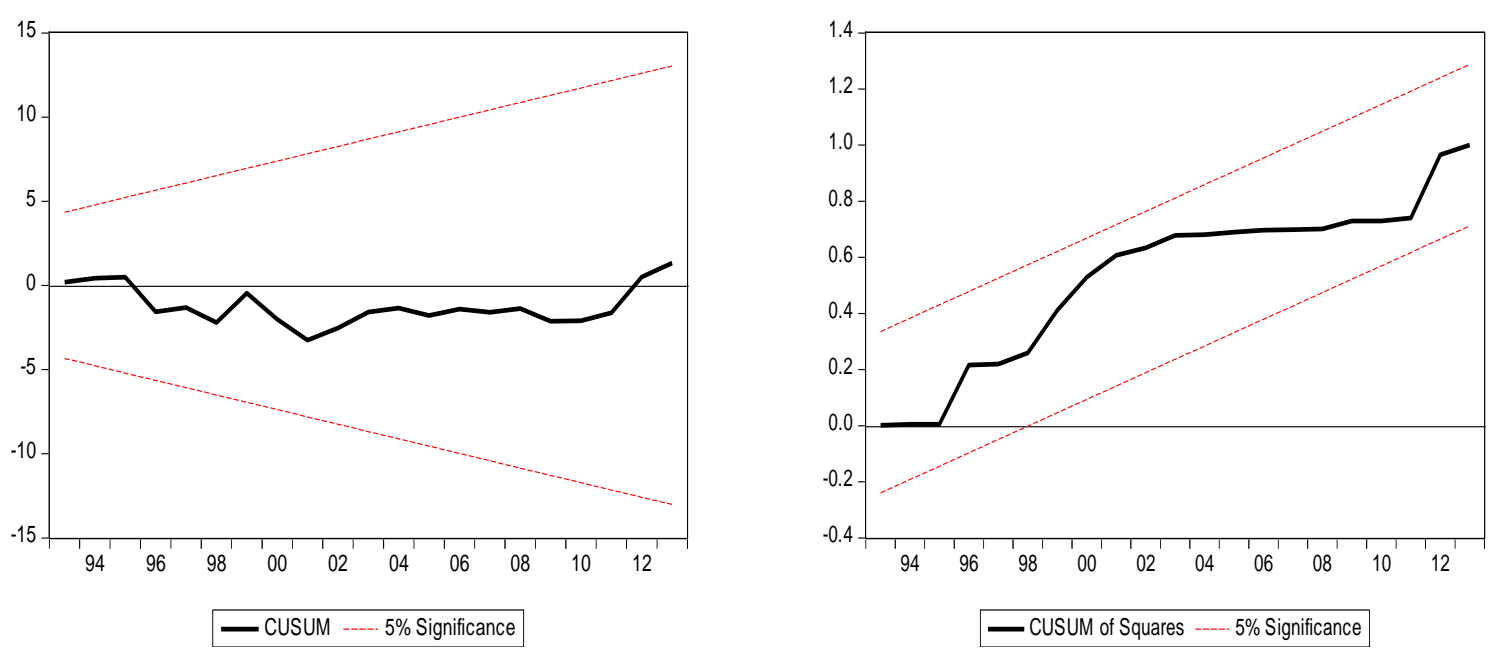

\section{Thailand}
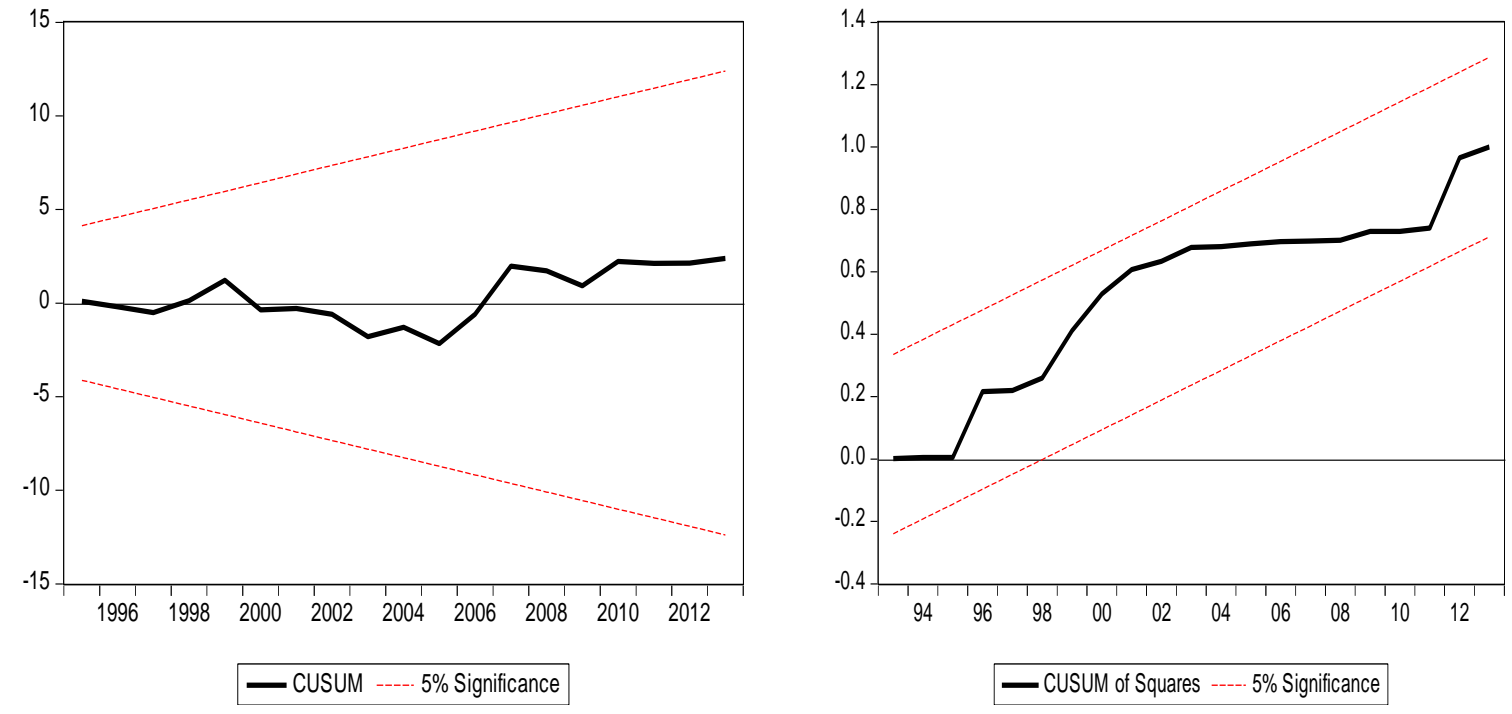

Fig 3 CUSUM and CUSUMSQ plots 
Table 1. Descriptive statistics

\begin{tabular}{|c|c|c|c|c|c|}
\hline & $I M R$ & $F R$ & $P H Y$ & GNI & $E D U C$ \\
\hline \multicolumn{6}{|l|}{ Indonesia } \\
\hline Mean & 1.746 & 0.515 & -0.932 & 2.830 & 1.574 \\
\hline Median & 1.766 & 0.473 & -0.875 & 2.819 & 1.626 \\
\hline Maximum & 2.056 & 0.738 & -0.540 & 3.556 & 1.923 \\
\hline Minimum & 1.389 & 0.368 & -1.430 & 1.925 & 1.104 \\
\hline Std. dev. & 0.203 & 0.128 & 0.259 & 0.400 & 0.249 \\
\hline \multirow[t]{2}{*}{ Jarque-Bera } & 3.071 & 4.943 & 3.380 & 0.739 & 3.390 \\
\hline & $(0.215)$ & $(0.084)$ & $(0.184)$ & $(0.691)$ & $(0.183)$ \\
\hline \multicolumn{6}{|l|}{ Malaysia } \\
\hline Mean & 1.153 & 0.495 & -0.324 & 3.419 & 1.733 \\
\hline Median & 1.113 & 0.538 & -0.385 & 3.454 & 1.760 \\
\hline Maximum & 1.638 & 0.687 & 0.204 & 4.018 & 1.873 \\
\hline Minimum & 0.838 & 0.293 & -0.634 & 2.602 & 1.440 \\
\hline Std. dev. & 0.267 & 0.121 & 0.264 & 0.374 & 0.116 \\
\hline \multirow[t]{2}{*}{ Jarque-Bera } & 3.804 & 3.711 & 3.514 & 1.5465 & 7.587 \\
\hline & $(0.149)$ & $(0.156)$ & $(0.172)$ & $(0.461)$ & $(0.022)$ \\
\hline \multicolumn{6}{|c|}{ The Philippines } \\
\hline Mean & 1.585 & 0.633 & -0.468 & 2.897 & 1.861 \\
\hline Median & 1.583 & 0.624 & -0.813 & 2.890 & 1.870 \\
\hline Maximum & 1.743 & 0.796 & 0.093 & 3.441 & 1.946 \\
\hline Minimum & 1.371 & 0.483 & -0.964 & 2.271 & 1.740 \\
\hline Std. dev. & 0.134 & 0.092 & 0.465 & 0.284 & 0.064 \\
\hline Jarque-Bera & 4.705 & 2.232 & 6.628 & 0.449 & 2.463 \\
\hline
\end{tabular}




$\begin{array}{lllll}(0.095) & (0.327) & (0.036) & (0.798) & (0.291)\end{array}$

\section{Thailand}

$\begin{array}{lccccc}\text { Mean } & 1.448 & 0.367 & -0.669 & 3.112 & 1.583 \\ \text { Median } & 1.448 & 0.307 & -0.632 & 3.248 & 1.495 \\ \text { Maximum } & 1.854 & 0.747 & -0.381 & 3.761 & 1.953 \\ \text { Minimum } & 1.053 & 0.145 & -0.924 & 2.283 & 1.176 \\ \text { Std. dev. } & 0.246 & 0.189 & 0.173 & 0.418 & 0.241 \\ \text { Jarque-Bera } & 2.923 & 4.585 & 3.008 & 2.407 & 3.000 \\ & (0.231) & (0.101) & (0.222) & (0.300) & (0.223)\end{array}$

Note: Figures in ( ) represent the probability values 
Table 2. Unit root test results

\begin{tabular}{|c|c|c|c|c|}
\hline \multirow[b]{2}{*}{ Variables } & \multicolumn{2}{|c|}{$\mathrm{ADF}$} & \multicolumn{2}{|c|}{$\mathrm{ZA}$} \\
\hline & $I(0)$ & $I(1)$ & $I(0)$ & $I(1)$ \\
\hline \multicolumn{5}{|l|}{ Indonesia } \\
\hline \multirow[t]{2}{*}{$I M R$} & -1.174 & $-4.388 *$ & -4.240 & $-5.012 *$ \\
\hline & & & [2007] & [1997] \\
\hline \multirow[t]{2}{*}{$F R$} & $-4.802 *$ & $-3.392 *$ & $-5.146 * *$ & $-6.806^{*}$ \\
\hline & & & [1992] & [1994] \\
\hline \multirow[t]{2}{*}{$P H Y$} & -1.785 & $-4.094^{*}$ & -2.956 & $-6.877^{*}$ \\
\hline & & & [1982] & [2006] \\
\hline \multirow[t]{2}{*}{ GNI } & -1.409 & $-5.840 *$ & -3.787 & $-6.700 *$ \\
\hline & & & [1998] & [1988] \\
\hline \multirow[t]{2}{*}{$E D U C$} & -2.020 & $-4.644^{*}$ & -4.378 & $-6.765^{*}$ \\
\hline & & & [1990] & [1989] \\
\hline \multicolumn{5}{|l|}{ Malaysia } \\
\hline \multirow[t]{2}{*}{$I M R$} & -2.293 & $-2.995 * *$ & -3.167 & $-5.198 * * *$ \\
\hline & & & [1999] & [1998] \\
\hline \multirow[t]{2}{*}{$F R$} & -1.149 & $-4.464 *$ & $-5.152 * *$ & $-6.553^{*}$ \\
\hline & & & [1997] & [1994] \\
\hline \multirow[t]{2}{*}{$P H Y$} & -2.377 & $-5.591^{*}$ & -2.702 & $-8.423^{*}$ \\
\hline & & & [2006] & [1999] \\
\hline \multirow[t]{2}{*}{ GNI } & -1.987 & $-3.229 * *$ & -4.226 & $-5.190 * *$ \\
\hline & & & [1998] & [1981] \\
\hline \multirow[t]{2}{*}{$E D U C$} & $-3.892 *$ & $-4.832 *$ & -2.804 & $-6.303^{*}$ \\
\hline & & & [2005] & [2005] \\
\hline
\end{tabular}




\section{Philippines}

$\begin{array}{lcccc}\text { IMR } & -0.372 & -3.280^{* *} & -4.313 & -6.456^{*} \\ & & & {[1996]} & {[1985]} \\ \text { FR } & -1.483 & -5.953^{*} & -4.234 & -5.479^{* *} \\ & & & {[1985]} & {[1990]} \\ & & & -4.390 & -5.400^{* *} \\ \text { GNI } & -1.064 & -3.661^{*} & {[1993]} & {[1993]} \\ & -1.160 & -3.274^{* *} & -3.552 & -5.296^{* *} \\ \text { EDUC } & & & {[1998]} & {[1987]} \\ & -1.482 & -3.832^{*} & -4.398 & -7.479 * \\ & & & {[1985]} & {[1982]}\end{array}$

\section{Thailand}

\begin{tabular}{|c|c|c|c|c|}
\hline \multirow[t]{2}{*}{$I M R$} & -1.221 & $-2.910 * *$ & -3.815 & $-5.096 * *$ \\
\hline & & & [1999] & [2001] \\
\hline \multirow[t]{2}{*}{$F R$} & -2.868 & $-3.081 * *$ & -3.956 & $-5.157 * *$ \\
\hline & & & [1982] & [1985] \\
\hline \multirow[t]{2}{*}{ PHY } & -0.088 & $-6.988^{*}$ & -4.007 & $-5.224 * *$ \\
\hline & & & [1988] & [1999] \\
\hline \multirow[t]{2}{*}{ GNI } & -1.631 & $-4.051 *$ & -4.083 & $-5.261 * *$ \\
\hline & & & [1997] & [1997] \\
\hline \multirow[t]{2}{*}{$E D U C$} & -1.412 & $-3.299 * *$ & -3.141 & $-7.242 *$ \\
\hline & & & [1987] & [1992] \\
\hline
\end{tabular}

Note: $(*),(* *)$ and $(* * *)$ denote significant at $1 \%, 5 \%$ and $10 \%$ levels, respectively. Break date are stated in [ ] 
Table 3. Optimal lag selection

\begin{tabular}{lcccc}
\hline \multicolumn{1}{c}{ Countries } & AIC & SBC & HQC & HJC \\
\hline Indonesia & $-37.226[4]$ & $-33.354[3]$ & $-35.623[4]$ & $-54.668[4]$ \\
Malaysia & $-37.059[4]$ & $-33.231[2]$ & $-35.461[4]$ & $-52.401[4]$ \\
Philippines & $-40.580[4]$ & $-36.147[4]$ & $-38.977[4]$ & $-37.281[4]$ \\
Thailand & $-41.189[4]$ & $-37.233[2]$ & $-39.586[4]$ & $-55.184[4]$ \\
\hline
\end{tabular}

Note: Figures in [ ] represent optimal lag selections. 
Table 4. The ARDL bounds test for co-integration

\begin{tabular}{|c|c|c|c|c|c|}
\hline \multirow{3}{*}{ Countries } & \multicolumn{5}{|c|}{ Bounds testing to co-integration $(k=4, N=40)$} \\
\hline & \multirow{2}{*}{ Optimal lag length } & \multirow{2}{*}{$F$-statistics } & \multicolumn{3}{|c|}{ Diagnostic tests } \\
\hline & & & $\chi_{\text {NORMAL }}^{2}$ & $\chi_{A R C H}^{2}$ & $\chi_{\text {SERIAL }}^{2}$ \\
\hline \multirow[t]{2}{*}{ Indonesia } & $(4,0,3,3,1)$ & $7.670^{*}$ & 0.477 & 2.573 & 0.231 \\
\hline & & & $(0.787)$ & $(0.108)$ & $(0.630)$ \\
\hline \multirow[t]{2}{*}{ Malaysia } & $(2,4,4,0,4)$ & $7.118^{*}$ & 1.121 & 0.010 & 1.973 \\
\hline & & & $(0.570)$ & $(0.917)$ & $(0.171)$ \\
\hline \multirow[t]{2}{*}{ Philippines } & $(4,3,2,3,2)$ & $14.175^{*}$ & 0.492 & 2.071 & 2.810 \\
\hline & & & $(0.781)$ & $(0.150)$ & $(0.103)$ \\
\hline \multirow[t]{2}{*}{ Thailand } & $(3,3,2,4,4)$ & $9.681 *$ & 0.883 & 0.033 & 2.752 \\
\hline & & & $(0.642)$ & $(0.855)$ & $(0.114)$ \\
\hline Significance & Lower bound & Upper bound & & & \\
\hline level & $I(0)$ & $I(1)$ & & & \\
\hline $1 \%$ & 3.290 & 4.370 & & & \\
\hline $5 \%$ & 2.560 & 3.490 & & & \\
\hline $10 \%$ & 2.200 & 3.090 & & & \\
\hline
\end{tabular}

Note: $(*),(* *)$ and $(* * *)$ denote significant at $1 \%, 5 \%$ and $10 \%$ levels, respectively. Critical values bounds are from Pesaran et al. (2001) and values in () represent the $p$-values. 
Table 5. ARDL long-run estimates

\begin{tabular}{lcccc}
\hline Dependent & \multicolumn{4}{c}{ Countries } \\
\cline { 2 - 5 } variable: IMR & Indonesia & Malaysia & Philippines & Thailand \\
\hline Constant & 1.610 & 4.902 & -0.392 & 1.260 \\
FR & 0.464 & $-0.891 * * *$ & $0.879 *$ & $0.990^{*}$ \\
& {$[0.993]$} & {$[-2.001]$} & {$[3.949]$} & {$[3.129]$} \\
PHY & $-0.229 * *$ & -0.420 & $-0.022^{* *}$ & $0.632 * *$ \\
& {$[-2.733]$} & {$[-0.940]$} & {$[-2.352]$} & {$[2.365]$} \\
GNI & -0.014 & $-0.695 *$ & $0.123 *$ & 0.078 \\
& {$[-0.384]$} & {$[-3.725]$} & {$[3.423]$} & {$[1.237]$} \\
EDUC & $-0.236 * * *$ & -0.421 & 0.212 & $-0.388 *$ \\
& {$[-1.896]$} & {$[-0.765]$} & {$[1.156]$} & {$[-4.659]$}
\end{tabular}

Note: $(*),(* *)$ and $(* * *)$ denote significant at $1 \%, 5 \%$ and $10 \%$ levels, respectively. Values in [ ] represent $t$ statistics. 
Table 6. ARDL-ECM short-run estimates

\begin{tabular}{lcccc}
\hline Dependent & \multicolumn{4}{c}{ Countries } \\
\cline { 2 - 5 } variable: IMR & Indonesia & Malaysia & Philippines & Thailand \\
\hline$\Delta F R$ & -0.556 & $0.689 * * *$ & $0.229^{*}$ & 0.047 \\
& {$[-1.679]$} & {$[1.919]$} & {$[6.616]$} & {$[0.190]$} \\
$\Delta P H Y$ & $-0.003 * *$ & 0.024 & $0.002^{*}$ & $0.034^{*}$ \\
& {$[-2.190]$} & {$[1.599]$} & {$[2.892]$} & {$[5.923]$} \\
$\Delta G N I$ & -0.000 & $0.030 * *$ & -0.001 & $-0.008^{* *}$ \\
& {$[-0.090]$} & {$[2.085]$} & {$[-0.513]$} & {$[-2.670]$} \\
$\Delta E D U C$ & $0.014 *$ & -0.018 & 0.007 & $-0.074^{*}$ \\
& {$[3.051]$} & {$[-0.735]$} & {$[0.944]$} & {$[-5.871]$} \\
$E C T_{t-1}$ & $-0.035^{*}$ & $-0.066^{*}$ & $-0.109 *$ & $-0.084^{*}$ \\
& {$[-7.302]$} & {$[-6.659]$} & {$[-10.261]$} & {$[-8.565]$}
\end{tabular}

Note: $(*),(* *)$ and $(* * *)$ denote significant at $1 \%, 5 \%$ and $10 \%$ levels, respectively. Values in [ ] represent $\mathrm{t}$ statistics. 